\title{
Perspective
}

\section{Prithvi Mata: Hindu Perspectives on Nature}

\author{
Joseph $\operatorname{Archer}^{1 *}$ \\ ${ }^{1}$ South Asian Studies, University of Colorado, Colorado, USA \\ *Corresponding author email: Joseph.Archer@ colorado.edu \\ https://doi.org/10.36018/dsiij.v15i.140
}

\begin{abstract}
Indian scriptures describe the unity of each individual with nature by stating I am the Son of Mother Earth (mother earth). I found two major takeaways from my interviews in India. Firstly, I was fascinated to see so much agreement on the concept of species dharma. This concept is, in my opinion, the strongest evidence of embedded Hindu ecological understanding. The concept is very applicable and accessible to average Hindus, making it a framework that, if promoted, can help modern India develop a stronger environmental ethic. Through my own observations I have commonly witnessed what I can only define as spiritual apathy. Walking across a bridge I watched a family dump bags of candy, wrapper and all, into the river. Hundreds of aluminum and plastic bowls from makeshift Ganga puja litter the shore of the river, with untold thousands lying at the bottom. The main cause behind the so-called 'ignorant practice' in Hinduism seems to be the failure of the priests. Indeed, there is a need of class of Brahmin who has attained a state of higher consciousness and can teach masses with their ancient wisdom. Literacy on the legacy of ancient wisdom is on the rise in India, allowing the less-educated to access religious texts in a way that they never have been able to. A woman, who was interviewed said, "if we take our own inner change seriously, than this will lead to outer change. If we change our vision and lifestyle, everything will shift. We must perceive nature, culture, and land as divine".
\end{abstract}

Keywords. Prithvi Mata, Mother Earth, Hindu Perspectives, Nature, Ganga, Pollution 
Today, the peaceful banks of the Ganga River are bursting with life. Birds perch in massive trees situated along its shores, and a deer stops with her calf to drink from her powerful waters. When the sun sets, bats depart from deep within the forest and fill the sky, setting out to begin their night of hunting. As the sun disappears, people begin to gather along the banks. The sounds of kirtan fill the air: harmonized chants and singing coupled with tabla drums and harmonium. Young priests, armed with flaming arati lamps, pay tribute to the Asta-Dikpala, deities who are the guardians of the eight directions. These Gods represent not just the directions, but also elements such as fire and water. As the ceremony commencences, the faithful offer puja to the river, who is also a Goddess. Puja offerings- bowls made from leaves, containing incense, flower petals, and candles- quickly begin to fill the waters along the banks until their flickering lights fade away downstream. This powerful ritual takes place twice a day every day in the Himalayan city of Rishikesh. Ceremonies such as this happen along the Ganga and other rivers thousands of times daily, and the faithful also offer puja to countless mountains, hills, and trees. To the faithful, there is certainly a connection between their spiritual practice and nature, however, this manifests itself in a number of ways. I conducted research in the holy Himalayan city of Rishikesh, interviewing Hindus from a variety of backgrounds to better understand this relationship.

Every respondent commented on the inherent spirituality of nature. One said,"We feel peace and know ourselves in nature. We feel God and connect with the beyond. We are in tune with divinity." A second respondent said, "Nature is a manifestation of God, it gives voice to God." Another said, "When we live in harmony with nature we are living in harmony with godly values."

Many respondents placed significant spiritual value on trees, with two people making an almost identical comment. One interviewee said, "You must ask forgiveness from a tree before you cut it down, because in the end you are cutting from yourself." Another interviewee said, "If you cut this tree you cut your sampannata (wealth). You're cutting yourself." When we receive oxygen or shade from a tree, we usually take this service for granted, but one man expressed the spiritual importance of tree worship, "When we receive a gift from a friend we say thank you, so why not trees too?" Another responded with a similar statement, "We should serve trees- they serve us!"

In one of my first interviews a man said "We are past the wild man from like 2,000 years ago." Confused, I pressed him to elaborate, he then said that we have, "Gone past what God wants for us, our purpose." Upon further reflection I understood this as an understanding of dharma from a species perspective rather than that of an individual. Because of human evolution, agriculture, and industrialisation, humans have stepped beyond our ecological niche. The man saw this as a great source of suffering for both humanity and the world as a whole.

This lead me to investigate concepts of species dharma, particularly with humans. I asked participants if they saw protection of nature as a religious duty with every respondent strongly agreeing. One said, "When we protect nature we are protecting our lives. If there was never nature, there would never be life." Another responded similarly saying, "Of course. It is us protecting ourselves. Because we rely on nature we should naturally protect our home. All life on earth is connected like a chain, if one link breaks it will affect the others. We are like family members." The most impactful response was, "It's not only our duty, but it should be automatic. Let the flowers bloom, they're not for a garland to be worn for ten minutes and disposed of. Protecting nature, as humans, is our divine purpose." These powerful responses show how environmentalism is second nature to many Hindus and directly tied to the spiritual path. It also displays a deep understanding of ecological systems and their fragility. Indian scriptures indeed describe the unity of each individual with nature by stating "O Bhoomi Mata, I am the Son of Mother Earth (mother earth)" (माता भूमि: पुत्रो अहं पृथिव्या:) [1].

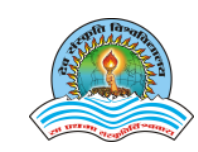


I met a yogi from Punjab (Indian State) who spends over an hour a day shoulder deep in the ice cold glacier water of the Ganga. He sees this powerful force of nature as a way to control his senses and breathing. I joined him for about fifteen minutes in the river, leaving after my entire body started shaking uncontrollably. He casually got out of the river and joined me for an interview on the beach. He told me in perfect English,"I was born to make this a better place, my dharm is to keep the earth clean. I am more concerned about nature than I am about worshiping Gods!" This yogi sees protecting and nurturing the natural world as a way to express devotion to the divine.

I found two major takeaways from my interviews. Firstly, I was fascinated to see so much agreement on the concept of species dharma. This concept is, in my opinion, the strongest evidence of embedded Hindu ecological understanding. The concept is very applicable and accessible to average Hindus, making it a framework that, if promoted, can help modern India develop a stronger environmental ethic. Also worth note is the logic of environmentalism from the nondualist perspective. It sees the destruction of nature as destruction of self. Because they understand humans as only a small part of the larger ecological and spiritual system, they understand that we only harm ourselves by causing harm to the environment.

\section{The Gap of Misunderstanding}

Yesterday evening I watched a man drown in the Ganga. I came to the shores for reflection, but instead watched helplessly from the shoreline as the powerful river dragged him into its crushing depths. It put into perspective the limitations of what we ask from the Ganga; what She can really give us and what She can take from us. Where is the true sacritity of the river found? What can The Goddess of the river offer us, and what can we offer Her in return?

Through my own observations I have commonly witnessed what I can only define as spiritual apathy. I've seen dozens of Indians come to the Ganga to strike a yogic or meditative pose for a picture and then quickly leave the river to go out to eat or stare at their phones in their hotels. Their entire interaction with the river is to pose for a photo. When they snap the picture, they attempt to depict a spiritual experience which they simply aren't having. They have the tools to begin their own spiritual growth; they know the yoga poses, they are clearly aware of some type of meditative science, but they simply refuse to actually commit to the practice. They would rather have the appearance of spirituality than actually have a spiritual experience.

Walking across a bridge I watched a family dump bags of candy, wrapper and all, into the river. This is not an isolated incident. I've seen people dump paper money into the Ganga. I watched as a family of monkeys was pelted with stones thrown by two grown men sitting near the river who made it a game to hit them. Hundreds of aluminum and plastic bowls from makeshift Ganga puja litter the shore of the river, with untold thousands lying at the bottom. If the philosophy of Hinduism is actually eco-conscious and environmentally friendly, then it begs the question: "What is going on?"

\section{Understanding the Causes}

The relationship between Hindus and the environment is a complicated one. I have seen well-intentioned travelers from across India pollute the river in their quest for self purity. I argue that although mistreatment of nature is in Hindu communities, it represents a degradation of values rather than a representation of complete values.

In the minds of many educated Indians, practices such as those that I observed are the result of misunderstanding and ignorant faith rather than a historically based practice. One respondent said,

People put plastic and flowers in the Ganga, therefore polluting it. This is not how you worship, you actually worship with the heart. The people who are doing this are not knowledgeable, not educated. This is a crisis of education, they don't understand what God is. They think spirituality is only rituals... (but) spirituality is the purification of emotions and feelings. It is the uplifting of thoughts. These people are ignorant. They don't read or understand the texts.

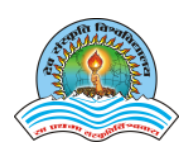


Another respondent said similarly, "Many people are not truly spiritual, they're dogmatic and traditional. They lack the sensitivity. These people are small children in the spiritual sense." One interviewee explained to me how he interprets peoples 'tributes' to the Ganga

We live in a world of shortcuts, take one coconut, throw it in Ganga, make a wish. These people aren't real Hindus. These people are considered 'educated' but they still hold these deep rooted superstitions. (The Ganga) is our mother- you wouldn't throw trash on your mother!

A group of men that I interviewed felt that the act of Ganga puja missed the mark entirely, "Ganga puja and watching tv are similar, they are a way to kill boredom, a way for people to temporarily focus their attention." One continued, saying, "If you don't harm nature you're always in puja. Accept the river as it is. This view (of the Ganga) alone is enough to see Shiva." They critiqued those who ask for fulfillment of wishes from the river, saying, "People who do this puja are another layer of greedy. They do puja for their own desires, but simply by craving you aren't being spiritual."

Among some educated and spiritual Indians there is an agreement that some people have a type of "spiritual threshold". Some people may simply lack the ability or will to understand complex spiritual concepts. When I asked someone how spiritual ignorance can be counteracted, he replied, "The dull can't understand, they will never, but if you educate them properly they will follow." A yogi echoed these sentiments, making another reference comparing those who lack spiritual awareness to children, saying,

Eighty percent of people are very low consciousness. They are like ten-year-old children... Sometimes you have to trick a ten- year-old into doing something that's good for themselves because they lack the ability to understand. Give a chocolate to a kid so they clean their room or do their homework. They need these (incentives). Some of them need a 'fear of God', they lack the integrity and discipline themselves so sometimes they need fear (to help them).

This quote tells us that among some of the spiritually inclined, there is an understanding that to fulfill larger societal goals, sometimes you must simply dictate religious dogma. This has historical precedent in other religions such as the Book of Leviticus in Christianity and the even more extensive cleanliness and dietary laws of Islam. These laws use the authority of religion to promote a secular agenda aimed at promoting public health and wellbeing. The more educated priest class may have attached these laws to religious dogma to ensure a more thorough adherence from the general population. It's not a big stretch to imagine the priests of India doing the same; imposing rituals and practices that protect the intricate systems of the natural environment. The Bhagavad Gita alludes to this in chapter 3 verse 21, "Whatever a superior person does, another person does that very thing! Whatever he upholds as authority, an ordinary person follows that." [2]. The understanding of the elite, at least at some point, was that protecting the delicate cycle of nature is important, but it may simply be more effective to enforce this through dogma rather than logic.

Interestingly, I discovered that many Hindus, including Brahmins themselves, blame ignorant religious practice on the priest class themselves. A Brahmin explained to me, "People have lost faith in the Brahmins. They lost their ethic. You have to earn followers, you have to first gain their respect." $\mathrm{He}$ went further to blame his own ancestors saying, "Even they didn't understand their own teachings. They didn't interpret the Vedas and Upanishads correctly." Another respondent echoed a similar sentiment, "Some priests don't understand. Their prime duty is to guide others and they have failed. To lead, priests must be selfless; what pollution we see in Hindus first comes from the priests. This is why the youth have lost faith in the priests." What I found most interesting here is the concept that although the central texts are valid, the misguided priests of today have failed to understand their own literature properly, losing sight of their ancestor's teachings.

Other critiques of Brahmins are far harsher, viewing them as a manipulative group that is more concerned with sustaining their place in power rather than promoting or sustaining positive values. One respondent said, "The Brahmin are cunning and

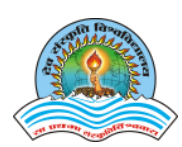


exploitative. They are the worst group of clever people." He went on further to explain their practice as big business, making money from maintaining ashrams that are, "Museums of better men". He also said that, "Religion is not spirituality." This challenges the entire concept of the structured religious system and the idea of Brahmins, viewing the entire religious institution as the root of the problem. Another repondant said, "Nature gave the keys to man to care for all life, but most people think that managing other people is more important." $\mathrm{He}$ identifies Ganga puja as a distraction that allows the Brahmins to maintain control, by simply giving people something to do. He said, "Instead of delving into real mystery they mystify any stupid thing."

The main cause behind the so-called 'ignorant practice' in Hinduism seems to be the failure of the priests. Perhaps they created Ganga puja as a way to control people; or maybe they made it to help the general population appreciate nature, but either way they have failed. Many fingers point at the priests, saying they have fallen short in their ability to pull Hinduism from the ashes of colonization and reestablish the dharma.

The Bhagvad Geeta (4/13), however, defines the Brahmin is not a cast. In Hinduism Brahmin was a class of men with higher consciousness achieved by their own selfless actions and virtues [3]. In addition, Skandha Purana describes that a man is no better than a sudra (of lower consciousness) at his birth, and one becomes brahmin (of higher consciousness) by Sanskaras (the qualities) [4]. Indeed, there is a need of class of Brahmin who has attained a state of higher consciousness and can teach masses with their ancient wisdom.

Literacy on the legacy of ancient wisdom is on the rise in India, allowing the less-educated to access religious texts in a way that they never have been able to. Texts such as the Bhagavad Gita and Upanishads are easily accessible and affordable at local bookstores in many languages. Many people who I interviewed agreed that this is a major way to uplift people from ignorance. A woman I interviewed said, "Communication (between the religious leaders and followers) should be strong. The educated should take responsibility and actually educate others about the texts." Similarly many people said that the spiritual should lead by example rather than doctrine, "If we take our own inner change seriously, than this will lead to outer change. If we change our vision and lifestyle, everything will shift. We must perceive nature, culture, and land as divine."

\section{Reflections}

On a shore a kilometer downstream from the Ganga puja, pilgrims gather with their families to take selfies on the shoreline. Last night they made offerings to the river, asking for prosperity, peace, or even a miracle, but some seem to miss the miracle happening before their own eyes. The flowers from last nights offerings have washed up along the shore. Bees have found the flowers and are quick to get to work pollinating. These little electrostatically charged creatures, tapped into an unimaginably complex system of interconnected consciousness, are working hard to keep the wheel turning. These tiny miracles will give life to the entire valley, pollinating plants as they perform their duty. Is this not enough of a miracle?

Can the mother goddess of the river give her devotees a successful fiscal year in 2020? Maybe, but we simply don't know. What we do know is she gives life to all those who ask it of her. She feeds the trees along her shores that provide all of us with oxygen. She waters the food that we eat. She gives clean, clear water to all of us who ask; the fish, the snakes, the birds, the deer, the elephants, tigers, dolphins, and humans; is that not enough?

\section{References}

1. Atharvaveda 12/1/12, Yugnirman Yojana Vistar Trust, Gayatri Tapobhumi Mathura, Mathura, India

2. Gita 3/21. Geetapress, Gorakhpur, 273005, India

3. Gita 4/13. Geetapress, Gorakhpur, 273005, India

4. Skanda Purana, Nagar Kanda, Chapter 239, Verse 3134, Geetapress, Gorakhpur, 273005, India 